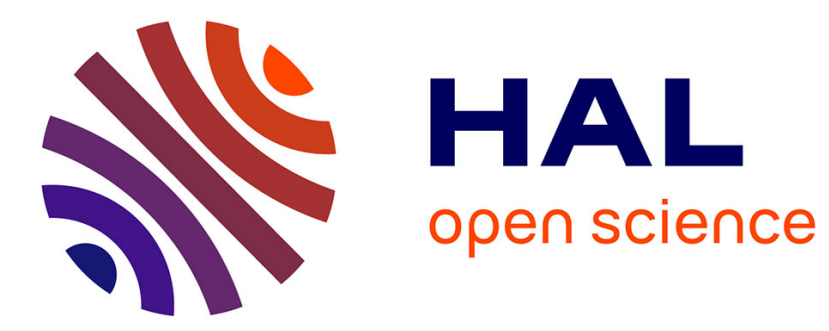

\title{
Web Technologies for Open Innovation
}

Darko Jesic, Jovana Kovacevic, Milan Stankovic

\section{To cite this version:}

Darko Jesic, Jovana Kovacevic, Milan Stankovic. Web Technologies for Open Innovation. WebSci, 2011, pp.1-6. halshs-00677760

\section{HAL Id: halshs-00677760 \\ https://shs.hal.science/halshs-00677760}

Submitted on 9 Mar 2012

HAL is a multi-disciplinary open access archive for the deposit and dissemination of scientific research documents, whether they are published or not. The documents may come from teaching and research institutions in France or abroad, or from public or private research centers.
L'archive ouverte pluridisciplinaire HAL, est destinée au dépôt et à la diffusion de documents scientifiques de niveau recherche, publiés ou non, émanant des établissements d'enseignement et de recherche français ou étrangers, des laboratoires publics ou privés. 


\section{Web Technologies for Open Innovation}

\author{
Darko Jesic \\ Université Paris-Dauphine, \\ DRM, Mlab \\ Place du Maréchal de Lattre de \\ Tassigny, 75775 Paris, France \\ 0144054405 \\ jesicdarko@gmail.com
}

\author{
Jovana Kovacevic \\ Université Paris-Dauphine, \\ DRM, Mlab \\ Place du Maréchal de Lattre de \\ Tassigny, 75775 Paris, France \\ 0144054405 \\ Hypios, 187 rue du Temple, \\ 75003 Paris, France \\ kovacevic.jovanaaa@gmail.com
}

\author{
Milan Stankovic \\ Université Paris-Sorbonne \\ 28 rue Serpente, 75006 Paris \\ 0140512511 \\ Hypios, 187 rue du Temple, \\ 75003 Paris, France \\ milstan@gmail.com
}

\begin{abstract}
The spread of the open innovation model created new challenges for further implications of the Web in making the innovation happen. In this paper we present a research on the application of the Web technologies in the open innovation model. We analyze technologies for expert search, key words matching and social propagation that would enable more efficient creation of new solutions, as well as transfer of solutions between different sectors. In addition, we made a triangulation of different open innovation paradigms in the function of Web technologies that serve for their realization. By such means, we are offering a framework that can help in making decisions and in choosing Web technologies according to wanted paradigms in an Open Innovation process.
\end{abstract}

\section{Keywords}

Open Innovation, Web, Key Words Matching, Social Propagation and Expert Search.

\section{INTRODUCTION}

In the increasingly competitive market that characterizes the world economy today, the need to develop innovations quickly has became the holly grail for many companies. Open innovation model emerged as a response to the limitations of traditional innovation model, involving mainly internal research departments performing innovation in companies. The traditional model has been perceived as unsatisfactory mostly in terms of efficiency and broadness of solutions considered. According to Chesbrough, "Open innovation is the use of purposive inflows and outflows of knowledge to accelerate internal innovation, and expand the markets for external use of innovation, respectively. Open Innovation paradigm assumes that firms can and should use external ideas as well as internal ideas, and internal and external paths to market, as they look to advance their technology" [1]. According to the existing literature, three key processes of the open innovation can be differentiated [2]: the process "outside-in" (the use of external resources), the process "inside-out "(the realization of profits from the commercialization of sleeping patents) and the process" coupled "(co-creation with partners). This paper is focalized on the outside-in processes realized via open

Permission to make digital or hard copies of all or part of this work for personal or classroom use is granted without fee provided that copies are not made or distributed for profit or commercial advantage and that copies bear this notice and the full citation on the first page. To copy otherwise, or republish, to post on servers or to redistribute to lists, requires prior specific permission and/or a fee.

WebSci '11, June 14-17, 2011, Koblenz, Germany.

Copyright 2011 ACM. innovation platforms.

Chesbrough has introduced the term of the "open innovation" in 2003 [3]. In turn, recent literature argues that "open" practices have been applied before in companies in different ways [4]. Even so, various case studies from practice show the successful application of the open innovation model and strategies, such as IBM, P\&G, Intel, Cisco Systems, DuPont, Lucent, Philips [5].

In this paper we observe the performance of open innovation model on the Web. Likewise, we analyze different Web technologies that could increase the performance of certain open innovation strategies.

In the section 2 , motivation, we shall present the facts that motivated this research. In Section 3 we identify companies that use open innovation processes and we list some of the first initiatives of the use of the Web as a tool for guiding and supporting open innovation processes. Afterwards, we identify some of main open innovation paradigms, as well as Web technologies whose application enrich open innovation processes. These two elements will be the basis for our analysis of the applicability of the Web technologies for open innovation scenarios. In the next part, we provide a mapping of the identified Web technologies to different open innovation paradigms. We suggest a framework for the use of Web technologies according to described paradigms. In the section 5 we introduce cases that demonstrate practical usefulness of Web technologies. In the section 6 , we describe certain limitations that the application of the open innovation model on the Web is facing nowadays. Lastly, in section 8 we summarize our research and we propose the future work directions.

\section{MOTIVATION}

Nowadays, everyone leaves different kinds of traces on the Web (ex. blogs, social networks, publications, images, videos, audio, etc.) that characterizes the users who left it. In order to identify potential solvers it is clear that we should use all data that users leave on the Web. Currently, there is a number of technologies that serve for connecting people on the Web, but they, to our best knowledge, have not been analyzed in literature in a context of open innovation models.

Consequently, our work is motivated by the following potential impact of the Web on the enrichment of the open innovation model:

- It is possible that solutions already exist somewhere, but the problem's owner is not conscious of them. Certainly, the Web enable easer access to the information and it fasten communication (knowledge is linked to a net and therefore easier accessible) and consequently it present one of the potential places for this. 

somewhere trying to resolve another problem. The Web advance human communication and make it faster, especially the Social Web, that could enable spontaneously the reach to the solution through the interaction of users. Of course, that interaction should be channeled in order to protect reveal or stole of ideas.

- It is possible that individuals who are not declared as experts, and who are not in the bases of experts, could possess knowledge that is essential for a solution of a part or a whole problem. On the Web, knowledge and interest of lots of users are transparent on their profiles and in their interactions with others. That sort of information could help them to apply their knowledge that they could hardly imagine how it could be useful, and at the same time they could help to problem's owner to find a solution.

- It is possible that there are companies that are on two corners of the world that are in the same field of practice. If they are not exploiting the same market, as they are far away from each other, they could propose solutions to each other. The Web provides better visibility of problems and enlarges a possibility for such parties to get in contact.

Therefore, in this paper we identify technologies that would make sense of all those data, which are findable on the Web, in order to feed problem-solving process in open innovation platforms.

\section{BEGINNINGS OF OPEN INNOVATION ON THE WEB}

Nowadays, a lot of companies benefit from the fact that majority of people spend a lot of time on the Web by leaving traces about their activities. For example, Facebook relies on that information in order to send personalized publicities to the users. We are especially interested in the type of companies that are using the Web for open innovation strategies, in order to actively include users in their problem solving process. The companies take diverse number of actions to take advantage of open innovation, such as providing simple interfaces for individuals outside the company to interact with their organization. For example, Procter \& Gamble was among the first companies engaged in a process of open innovation. $P \& G$ has developed its Connect + Develop website ${ }^{1}$ to get in touch with external innovators, so that they could contribute through propositions of solutions to $P \& G$ problems. This is an example of Web initiative for the development of a strategy of open innovation.

With the development of online social networks and other Social Web tools, the Web has become a platform for collaboration. In a synergy with the Social Web, the open innovation model has triggered the growth of intermediaries through open innovation platforms (ex. Hypios ${ }^{2}$, Innocentive ${ }^{3}$, NineSigma ${ }^{4}$ ) who are putting in contact, on the one hand, the companies (seekers) who are struggling to solve their R\&D problems and, on the other hand, a large network of potential solvers, i.e. individuals or groups who are more likely to have a solution to business problems. The emerging open innovation platforms are trying to leverage the Web technology, and most notably its social aspects to help innovation happen on the Web.

\footnotetext{
${ }^{1}$ Open innovation platform developed by Proctor \& Gamble www.pgconnectdevelop.com

${ }^{2}$ http://www.hypios.com

${ }^{3}$ http://www.innocentive.com

${ }^{4}$ http://www.ninesigma.com
}

In our research we focus on the company Hypios that runs an open innovation platform. Also, Hypios enabled us fully access to the needed data for this research. What is more, Hypios applies the largest variety of technologies in open innovation processes that gave us the opportunity to analyze those technologies and their application. One of the peculiarities of Hypios is the use of Semantic Web technologies that allow them to search for people, groups or organizations on the Web that are most likely to respond to problems that are placed on the platform. In addition, Hypios practices open innovation through the use of the Social Web by connecting various parties who have interest to work together over the Social Web channels, and posts its innovation challenges for spreading through the online social networks. Therefore, it represents a new model of open innovation that applies the Social and Semantic Web technologies in the concept of open innovation, different to traditional models. We call this process "Out-WebIn" [6] that represents innovation intermediaries who use active search procedures and selection of experts, including the Social Web and the Semantic Web. As the social and semantic aspects of the Web are among today's most vivid Web-related research areas, Hypios represents a fruitful source of data for studying the impact of the Web as an evolving phenomenon on the open innovation process, and their potential to support innovation on the Web.

\subsection{Related Work}

There are several research approaches related to the application of different aspects of the Web in the open innovation model. In the study [7], a content recommendation tool based on peopleto-people interaction is used in order to trigger creation of new ideas. Some studies underline that Social Web tools for collaboration provide cooperation and exchange of knowledge and ideas between different actors [8] and [9].

Although, in the mentioned work above the impact of certain aspects of the Social Web is analyzed, there are not many works that analyze the use of the Semantic Web, as an important facet of the Web phenomenon. Of particular interest for the Open Innovation topic is the use of Semantic Web technologies in finding experts in domains lateral to the problem by application of semantic proximity analysis of key words. As the ability to collect solutions from lateral and unexpected domains is critical to achieving diversity in open innovation, in this paper, we focus on the role of Semantic Web based keyword exploration of lateral key words in finding experts for open innovation scenarios. Therefore, we investigate the potential impact of a variety of today's Web technologies that could help the open innovation model. We take in concern some aspects and concrete technologies that are related to the systematic application of the open innovation concept. Using the case studies we would like to show the practical use of some concrete Web technologies explained latter in the paper.

\section{WEB TECHNOLOGIES AS SUPPORT FOR OPEN INNOVATION PARADIGMS}

\subsection{Open Innovation Paradigms}

Although, numerous publications are related to the field of the open innovation, there is still a lot of unexplored aspects and consequences of these developments in the innovation process to which this paper refers. Academic research in open innovation differentiates several research approaches that are being applied in different situations. In this section we provide an overview of some of the most important paradigms in open innovation processes, on which we will base our further analysis. 


\subsubsection{Social Behavior on the Web - "Weak Ties"} Several theories have already been presented to explain the social behavior of people on the Web and to the Open Innovation process. According to Granovetter's work [10] on the nature of human relationships and his network theory of social influence on the strength of weak ties, interpersonal relationships in networks have two basic forms: 1) we develop close ties, which are based on our immediate work and life contexts, and are at the heart of our respective networks, and 2) we develop weak ties that extend beyond our direct contexts in other areas and are on the periphery of our networks. Even if our ties are strong and regular, our weak ties are casual and we act as bridges between different social peripheries. This aspect of week ties enables much faster spread of ideas, problems, i.e. solutions between different parties in the open innovation processes.

\subsubsection{Cross-Sectorial Problem Solving}

According to Lakhani's theory [11] of "cross sectorial problem solving" if the company fails to resolve the problem internally in the organization, it is because very often the solution for this problem exists but in another sector. In the Lakhani's study, solvers created solutions to the problem that were at the border or outside their area of expertise, which shows us that opening the science may trigger the transfer and transformation of knowledge from one science to another.

\subsubsection{Broadcasting}

In the context of our work, broadcasting represent the distribution of different content related to problems to a dispersed audience via the Web technologies. Recently, strategies of broadcasting have been employed in problem solving processes that focus on broadcast of the problems to diverse and peripheral problem solvers [11]. Lakhani highlights the effectiveness of the search for solution via problem "broadcasting" by illustrating its application to 166 problems on the InnoCentive website. Research shows that the rate of solved problem, which could not be solved internally, through the spread to outside experts, represents $29.5 \%$.

Also, we should emphasize that platforms can search solvers in two ways, active and passive. A passive search may be the launching problems on the platform on the Web, but without any further action to attract solvers. Active search, conventionally presents searching by advertising, by using techniques such as segmentation. Moreover, active research advance significantly the mobilization of new technologies for highly personalized targeting, such as the use of the Semantic Web.

\subsection{Identified Technologies for Open Innovation}

Although there is work on the online search [12], the work done in relation to the use of social networks and new technologies by innovation intermediaries are not very numerous. Particularly interesting, the Social Web and Semantic Web present powerful tools for building and maintaining relationships of social communities dispersed to create and expand networks, to produce synergies through combined interactions of users [13]. Therefore, in this section we will discuss Web technologies that are likely to be useful in problem solving processes on the open innovation platforms. Of course, the list of identified Web technologies is not exhaustive as it is limited to the literature review and case studies perceived by authors, hence it could be increased in the future.
The possibilities of the Web to serve as a source for expert finding have already been studied in literature [14] and [15]. Web resources that users create or interact with have been used to assess expertise for the tasks, such as human resource management, finding help in e-learning scenarios etc.

\subsubsection{Practical Realization}

Recently, new trend has emerged regarding a form of publishing data on the Web: Linked Data. In contrast to representing data in a form of a regular Web pages, Linked Data represent a method of publishing data in a more structured format with more explicit semantic of the information. Some possibilities of the currently available user data in Linked Data form to serve expert finding have been presented in [14], and further benefits can be achieved once the data publishers accept richer forms of expressing expertise-related data [16].

\subsubsection{Semantic Keyword Matching}

Semantic keyword matching extends the standard matching of documents by keywords with a notion of semantic proximity of keywords that allow broadening the space of matching possibilities and go beyond the exact match. This property of semantic keyword matching presents a real need in the open innovation model.

\subsubsection{Practical Realization}

Different communities use different words to express the same or similar concepts. Thus coming from one community of practice and using one's own words to express an innovation problem may be a limitation to the visibility of the problem in other fields. Some existing technologies can significantly help in finding synonyms and words of similar meaning, based on taxonomies of concepts [17] and word co-occurrence [18]. Existing approaches however, have some limitations as they focus on providing relevant suggestions and often neglect the need for serendipity and discovery that are essential to open innovation scenarios. Novel approaches that use Linked Data sources, such as DBPedai.org to make meaningful connections between concepts in the musical domain [19] and enable discovery of unexpected but relevant concepts give hope that such sources might also serve to establish a notion of semantic proximity of concepts, that would be more open to serendipity.

\subsubsection{Social Propagation}

Facebook and other social networks have become one of principal ways in which people receive information nowadays. Facebook have already been mentioned in literature in marketing studies and it has been used for promotion of content or information of the different nature [20]. Therefore, in order to reach target audience these channels of communication should be used in broadcasting of the open innovation challenges.

\subsubsection{Practical Realization}

By using the technologies for expert identification and semantic matching of keywords from the problem with the keywords from a user profile, would enable to intelligently propagate the problems through the Social Web channels. This would increase the visibility of problems and, at the same time the chances of reaching an innovative, potentially already existing solutions. A special advantage of such an approach is the fact that information is re-shared and re-posted among users in social networks - a practice that gives additional relevance to the shared content. Therefore, we explore the impact of the Social Web communication channels on the open innovation problem broadcast through a case study from our practice at hypios.com.

\subsubsection{Expert Finding}




\section{MAPPING THE SPECIFIC WEB TECHNOLOGIES TO DIFFERENT OPEN INNOVATION PARADIGMS}

In this section we describe the implications of Web technologies in open innovation strategies. Our aim was then to identify the match of a relevant technology with an open innovation paradigm.

In the following table we have summarized what technologies can be used for each paradigm analyzed in this paper.

Table 1 Technologies used for different paradigms

\begin{tabular}{|c|c|c|c|}
\hline $\begin{array}{c}\text { Paradigms / } \\
\text { technologies }\end{array}$ & $\begin{array}{c}\text { Expert } \\
\text { finding }\end{array}$ & $\begin{array}{c}\text { Semantic } \\
\text { keyword } \\
\text { matching }\end{array}$ & $\begin{array}{c}\text { Social } \\
\text { propagation }\end{array}$ \\
\hline "Broadcasting" & & & $\mathrm{X}$ \\
\hline $\begin{array}{c}\text { "Cross- } \\
\text { sectorial } \\
\text { problem } \\
\text { solving" }\end{array}$ & $\mathrm{X}$ & $\mathrm{X}$ & \\
\hline "Weak ties" & $\mathrm{X}$ & $\mathrm{X}$ & \\
\hline
\end{tabular}

\subsection{Expert Finding - Application in Open Innovation}

The challenges that expert finding has to resolve in the open innovation are different: it is essential to find potential problem solvers, that are not necessarily the best ranked experts, with riche experience in the problem domain [20]. The growing amount of user data and data about users that is collected on the Web every day represents a special potential for using the Web to help benefit both knowledge seekers, and knowledge holders.

Thus, "expert finding" technology can be used to reach the outside solvers, including the one on the margin of the field in question, and to trigger the transfer of knowledge between those fields. In doing so, it enables the realization of "cross-sectorial problem solving" paradigm. Likewise, by identification of experts from peripheral fields, this technology helps to determine the graphs of social behavior between the relevant solvers on the Web and consequently identification of "weak ties".

\subsection{Semantic Keyword Matching Application in Open Innovation}

In the task of matching a problem description to profiles of potential experts, semantic matching would allow to include the experts who work not only in the exact domains of the problem but also in the domains that are semantically relevant to the problem domains. One of the primary motivations for using a broader matching approach is the difference in languages and concepts used in different expert communities that might need to be brought together in an open innovation process in order to increase the diversity of solutions.

Similarly to expert finding, this technology provides the identification of peripheral domains and relevant experts and thus helps realization of the following paradigms: "crosssectorial problem solving" paradigm and "weak ties" paradigm.

\subsection{Social Propagation - Application in o Open Innovation}

Facebook has developed different ways to share the information within the social network by allowing interaction of users with the content (ex. commenting posts, re-posting, "liking"). Indeed, those actions enable greater visibility of the information in the social circle of the user. Consequently, the intelligent selection of the initial user to put the information in his social circle is very important. Thus, it is essential that innovation problems can reach the potential solvers on such communication channels.

To conclude, social propagation technology is used when the open innovation process requires the broadcasting of the problem to the wider circle of potential solvers.

Again, the aim of this study is to facilitate the decision on making how to proceed with open innovation process according to the required paradigm. Therefore, this framework allows choosing the tools for the implementation of specific open innovation paradigms. Thus, it represents one of main contributions of this paper.

\section{CASE STUDIES}

In this paper we propose one case study from one of the recent challenges from Hypios that underlines the impact of social propagation on the visibility of broadcasted problems. Also, we identify the second case from Netflix prize competition that shows how new technologies can help to identify more concepts related to the problem in order to reach potential solvers.

\subsection{Research context}

We have chosen the company Hypios that has a role of an intermediate between companies that search for solutions of their R\&D problems, and solvers who supply various solutions to them. In its approach, Hypios use various Web technologies in order to select solvers who would be most able to resolve a problem. Therefore, we use one of their cases that shows the application of Web technologies in the open innovation model.

\subsection{Case Study 1}

Social networks, such as Facebook, Twitter, and LinkedIn have registered an important growth and have been analyzed as a dynamic way for communication and sharing of information. Consequently, this case is focusing on advantages of social propagation technology via socials networks.

Recently, a client of Hypios was interested in getting to know the scientific community better, and particularly to be fluent in its language and concepts ${ }^{5}$. They wanted to design a system able to learn the vocabulary and concepts of a scientific domain, and to identify the relationships between domains. The company decided to broadcast this problem on the Hypios platform in order to find a relevant solver or to identify existing solutions that could be applied to their problem.

As Hypios is using social propagation technology, Hypios broadcasted the problem via social networks that enabled a greater visibility of the problem. As a consequence, it contributed to a larger number of solvers, which further led to the identification of a solver who proposed an interesting solution to their problem. Interestingly the solver was not in Hypios base of experts, hence this solver was informed about the problem by his previous $\mathrm{PhD}$ supervisor who further received this information from his manager at the University where he has been working as a researcher. Professor forwarded the link to the problem through a social web channel, where it caught the student's attention. As the problem was closely related to one of the student's topics in his $\mathrm{PhD}$ research, he

${ }^{5}$ The problem about the Automatic discovery of scientific domains, and their relationships http://www.hypios.com/problems/archive/page/2 
used his knowledge about these topics to create a solution that has been picked as a wining solution.

Again, social propagation of the problems through the Social Web channels can increase their visibility and thus the chances of reaching an innovative or potentially already existing solution. At the same time, this case shows how social propagation enable reaching out the individuals who did not opt in as experts in one of the expert databases. In addition, this model gives the opportunity to people who are not conscious that their knowledge could have an application in some field. Through social propagation they can find out different ways how to put their knowledge in function of others needs. Therefore, this case shows an important role of social propagation technologies for problem-solving processes in open innovation practices.

\subsection{Case Study 2}

In this study we further elaborate the use of technologies based on Semantic keyword matching for the open innovation expert finding. Those technologies can help to discover and to identify related topics and concepts that are somehow relevant to the seeker's problem in question. In the basic concept, seekers are posting their problems on the open innovation platforms and they are expecting from the website, such as Hypios, to be able to invite and to identify the solvers that are most capable to solve the problem. We analyzed here a technology that is extracting keywords from the problem description helping to identify concepts and solvers that are relevant or related to the problem context. In order to generate semantically related keywords that would allow us to broaden the conceptual space in which one could look for potential solutions, we have used a proprietary tool developed by Hypios, called hyProximity ${ }^{6}$. HyProximity uses the Semantic Web version of Wikipedia DBPedia.org to generate relevant topic suggestions for the given input topics. The functioning of the hyProximity allows to discover relevant, but some unexpected topics, by traversing the graph of topic relations and finding those topics that are related to one, or preferably several initial input topics. This yields a set of suggestions that are semantically close to the conceptual space defined by the initial set of topics; and that are not necessarily synonyms. The advantage of this approach is that it does not depend on concurrence of topics in texts - it relies on the connections defined by the meaning of topics and, thus, it allows discovering topics not used together before - that have the potential of being used by distinct communities of practice.

For this experiment, we used a description of the Netflix prize problem accessible on the Web. ${ }^{7}$ In doing so, we only used a part of the problem description, i.e. the beginning of the description that does not contains the elements of a solution.

Netflix prize competition had a similar scenario to the open innovation platform websites. Netflix broadcasted a problem description on their site along with a prize definition and a deadline in order to motivate teams and individuals to work on problem resolution.

\subsubsection{Results}

In our case, hyProximity gave quite broad results. Interestingly, in the first part of results, that is more precise and related to the topic, we found the key words such as: artificial neural network,

${ }^{6}$ hyProximity is described on the following website http://research.hypios.com/?p=170

${ }^{7}$ http://en.wikipedia.org/wiki/Netflix_Prize\#Problem_and_data sets online learning model, machine learning, that are obviously related to the topic. In addition, further results such as: expectation-maximization algorithm, data proliferation, pattern recognition are relevant and related to the problem solutions. Finally, we identify the key words as: index of dispersion, risk function, constrained conditional models, that are giving clues about possibly relevant domains and are giving precisions about the domains that are evidently related to the topic. Among the first 20 hyProximity suggestions that were not found in the initial Netflix problem description we found the concept "Principal Component Analysis", that was in fact used by researchers on the Netflix Dataset. This concept thus identifies a viable approach to take in solving the Netflix problem [22].

From our point of view, this case shows how new technologies can help more in the open innovation model and more precisely how they can help to identify concepts and solvers related to the problem broadcasted on open innovation platforms.

\section{CURRENT LIMITATIONS OF THE OPEN INNOVATION MODELS ON THE WEB}

\subsection{Corporate Culture and Web-Phobias}

The model of open innovation platforms who are using Web technologies is yet to achieve a wider acceptance due to people's fear of the Web and its application. There are people who are not using it within a company. In order to overcome this obstacle, corporate learning about use and advantages of the Web are more than necessary,

\subsection{Confidentiality and Trust}

Further, it seems that some people are afraid of the consequences that openness and posting of a problem on the Web could bring. If they post a problem publicly they are afraid that someone else could try to work on similar problems. There is also a fear for Solvers that they could not be paid for their contributions.

As a solution to this limitation, it is obligatory to develop clear contracts and intermediate services, that assure legally users against abuse, as well as to introduce different level of privacy for problem description access, as Hypios does.

\subsection{Privacy}

All users' traces on the Web characterize the users who left them, and represent at the same time a danger for users privacy and an opportunity for the user and his knowledge and skills to be recognized by others. If the identification of users' competencies is based on the public data that users leave voluntarily, the way of contacting potential solvers should be taken in concern in order to protect users' privacy. Actually, users should be contacted prudently, in a non-intrusive manner, as the users could control if they would like to be contacted. In that way, the use of those public data should present more an opportunity than a threat for users. Nevertheless, we emphasize that the border between an opportunity and the threat of the use of users data is tiny and therefore the Web design for open innovation should be done with great attention respecting the users' privacy.

\section{CONCLUSIONS AND FUTURE WORK}

In this paper we investigated the importance of use of technologies based on the Social Web and the Semantic Web in the Open Innovation challenges. We explained that those technologies allow the search of solvers who are most able to solve the problem posted, but that are not strictly in the same 
field or sector. In addition, we have given the framework that suggests the use of particular technologies for specific open innovation paradigms. Through two study cases we have demonstrated the use of the Semantic Web technologies and the influence of Social Propagation in the Open Innovation challenges.

In future work, we plan to develop Web technologies that would suggest keywords to be used in the problem formulation. In addition, we would further research possibilities of creation of teams of experts according to the traces they left on the web. Also, we plan to apply the technology of key word matching in the process "inside out" in order to test them in searching for the potential clients for the sleeping patents, i.e. unused solutions.

\section{ACKNOWLEDGEMENTS}

The Authors would like to thank to the supervisor Prof. Albert David for his guidance.

\section{REFERENCES}

[1] Chesbrough, H. W., Vanhaverbeke, W., and West, J. (Eds.). 2006. Open innovation: Researching a new paradigm. Oxford: Oxford University Press.

[2] Enkel E., Gassmann O., and Chesbrough H. 2009. Open $R \& D$ and open innovation: exploring the phenomeno. $\mathrm{R} \& \mathrm{D}$ Management, 39, 4, 311-316.

[2] Granovetter M. 1985. Economic Action and Social Structure: The Problem of Embeddedness. American Journal of Sociology, 91(November).

[3] Chesbrough, H. 2003. Open Innovation: The New Imperative for Creating and Profiting from Technology. Harvard Business School Press: Harvard, MA.

[4] Trott, P., Hartmann, D. 2009. Why 'Open Innovation' is old wine in new bottles. International Journal of Innovation Management, 3 (4), 715-736.

[5] Sari, V., Salmi P., Torkkeli M. 2007. Implementation of open innovation paradigm: Cases: Cisco Systems, DuPont, IBM, Intel, Lucent, $P \& G$, Philips and Sun Microsystems. 978952-214-478-2, 189, ResearchReport, Lappeenranta.

[6] Jesic D., Kovacevic J. 2010. L'innovation ouverte: exploration et enjeux d'un modèle "Out-Web-In". Master thesis, Université Paris-Dauphine.

[7] Santonen, T., Suomala, J., Kaivo-oja, J. 2008. Brief introduction to the national open innovation system (NOIS) paradigm: supporting individual creativity in an online social network with content recommendation. The proceedings of the XIX ISPIM conference, Tours, France, 15-18 June 2008.

[8] McAfee, A. 2009. Enterprise 2.0: New Collaborative Tools For Your Organization's Toughest Challenges. Harvard Business Press.

[9] Carlsson, S., Corvello, V., Magliares, P. 2009. Enabling open innovation : Proposal of a Framework supporting ICT and KMS implémentation in Web-based intermediaries. 17th European Conference on Inforamtion Systems, ECIS, Verona.

[10] Granovetter, M. 1983. The strength of weak ties: a network theory revisited. Sociological Theory, Volume 1 (1983), 201233.

[11] Lakhani, K.R., Jeppesen, L.B., Lohse, P.A., Panetta, J.A. 2007. The value of openness in scientific problem solving, Working paper, Boston: Harvard Business School.
[12] Parkes, D. C. 2007. Online Mechanisms. In Nisan, N., Toughgarden, T., Tardos, E., Vijay V. V. (Eds.). Algorithmic Game Theory, Cambridge University Press, 411-439.

[13] Breslin, J., Passant, A. and Decker, S. 2009. The Social Semantic Web. Heidelberg: Springer-Verlag.

[14] Stankovic, M., Wagner, C., Jovanovic, J., and Laublet, P. 2010. Looking for Experts? What can Linked Data do for You?. In Proceedings of Linked Data on the Web 2010, Raleigh, NC.

[15] Stankovic, M. 2010. Open Innovation and Semantic Web : Problem Solver Search on Linked Data. In Proceedings of International Semantic Web Conference (ISWC) 7th-11th Novebmer, Shanghai, China.

[16] Aleman-Meza, B., Bojars, U., Boley, H., Breslin, J. G., Mochol, M., Polleres, A., et al. 2007. Combining RDF vocabularies for expert finding. Lecture Notes in Computer Science, 4519, 235. Springer. Retrieved from http://www.springerlink.com/index/p6u10781711xp102.pdf.

[17] Ziegler, C.-N., Simon, K., and Lausen, G. 2006. Automatic Computation of Semantic Proximity Using Taxonomic Knowledge Categories and Subject Descriptors. CIKM '06 Proceedings of the 15th ACM international conference on Information and knowledge management (pp. 465-474). Arlington, Virginia, USA: ACM New York, NY, USA. Retrieved from http://doi.acm.org/10.1145/1183614.1183682.

[18] Cilibrasi, R. L., and Vitanyi, P. M. B. 2007. The Google Similarity Distance. IEEE Transactions on Knowledge and Data Engineering, 19(3), 370-383. doi: 10.1109/TKDE.2007.48.

[19] Passant, A. 2010. dbrec - Music Recommendations Using DBpedia. In P. F. Patel-Schneider, Y. Pan, P. Hitzler, P. Mika, L. Zhang, J. Z. Pan, et al. (Eds.), Proceedings of the 9th International Semantic Web Conferene - ISWC 2010 (Vol. 1380, pp. 1-16). Shanghai, China: Springer Verlag.

[20] Hastings, G. 2007. Social Marketing - Why should the devil have all the best tunes? Elsevier Ltd.

[21] Jeppesen, L. B., and Lakhani, K. R. 2009. Marginality and Problem Solving Effectiveness in Broadcast Research. Organization Science, 20. Retrieved from http://dash.harvard .edu/handle/1/3351241.

[22] Raiko, T., Ilin, A. and Karhunen, J., 2007. Principal component analysis for sparse high-dimensional data. In Proceedings of the 14th International Conference on Neural Information Processing (ICONIP 2007), Kitakyushu, Japan. 